\title{
Perceptions and opinions of graduating South African optometry students on the proposed community service
}

\author{
KP Mashige ${ }^{\mathrm{a}}$, OA Oduntan ${ }^{\mathrm{b}}$ and N Rampersad ${ }^{\mathrm{c}}$
}

Discipline of Optometry, School of Health Sciences, University of KwaZulu-Natal, Westville Campus, Private Bag X54001, Durban, 4000 South Africa

a'<mashigek@ukzn.ac.za $>$ b $<$ oduntanoa@ukzn.ac.za $>$ c $<$ rampersadn@ukzn.ac.za $>$

Received 14 August 2012; revised version accepted 31 January 2012

\begin{abstract}
Community service (CS) was introduced in South Africa in an attempt to address the shortage and maldistribution of health care professionals within the public sector. The Professional Board for Optometry and Dispensing Opticians (PBODO) has approved legislation for the introduction of CS for graduating optometry students. This study examined the perceptions and opinions of graduating optometry students regarding the proposed CS. A mixed-method design (questionnaires and interviews) was used. Both approaches yielded similar results. The quantitative component included 119 participants, aged between 20 and 35 years (mean age and standard deviation; $22.8 \pm 2.3$ years). There were $43.2 \%$ Blacks, $28.5 \%$ Whites, $19.1 \%$ Indians and 9.2\% Coloureds. The qualitative part included fourteen participants from the Optometry Department of the University of KwaZulu-Natal. The major themes emerging
\end{abstract}

from the questions concerning the participants' perceived advantages and benefits of CS were (i) it would improve the eye care service delivery to disadvantaged communities; (ii) it would improve the technical and clinical skills of the graduating optometrists and (iii) it would enhance their confidence, personal and social skills. Some of the perceived drawbacks cited by the participants about such service included poor remuneration and concerns about personal safety, transport and accommodation. The findings of this study suggest that graduating optometry students acknowledge the importance of CS in improving access of many South Africans to quality eye care. In order to maximise the full benefits of CS, all stakeholders need to address the highlighted concerns of the participants. (S Afr Optom 2013 72(1) 11-18)

Key words: community service, public health optometry, South African optometry students, training and teaching, education

\section{Introduction}

Community service (CS) entails graduate healthcare professionals working in state health care facilities for a mandatory period of, usually, one year upon completion of their academic qualifications ${ }^{1}$. In South Africa, CS has emerged as a symbol of the commitment of the Department of Health $(\mathrm{DoH})$ to ensure equity in the public health services as well as an attempt to address the shortage of health care professionals in that sector particularly in rural and under-resourced areas ${ }^{2}$. CS also provides young professionals with an opportunity to further develop and acquire knowledge and skills ${ }^{3}$. The first CS for health professionals in South Africa was implemented in 1988 with 26 medical doctors commencing this innovation in July of that year ${ }^{4}$. The 
initial announcement regarding the implementation of CS for medical doctors was negatively received by those who were affected by the ruling ${ }^{4,5}$. Their concerns included the perception that CS would hinder their career plans, the inconvenience of being placed in rural environments and poor remuneration which would make it difficult to repay their student study loans ${ }^{4,5}$. Many of the affected medical doctors even threatened to emigrate to avoid $\mathrm{CS}^{4,5}$. However, subsequent findings indicated that the majority of those eligible for CS did take up their posts ${ }^{4,5}$. Regulations for other health service disciplines including dentists, pharmacists, physiotherapists, occupational and speech therapists, clinical psychologists, dieticians, radiographers and environmental health officers were promulgated in subsequent years ${ }^{1}$. For those health service disciplines where CS has been implemented, it has become a pre-requisite for professional registration with the Health Professions Council of South Africa (HPCSA) ${ }^{1}$.

The eye care services between rural and urban areas in South Africa are skewed, with a large concentration of activities in urban areas ${ }^{6}$. The lack of eye care facilities and personnel in rural areas results in many people suffering from visual impairment and even blindness possibly from avoidable and treatable eye conditions thereby suggesting the need for an urgent review of the rural-urban eye care resource distribution ${ }^{6}$. Public sector institutions, in most provinces, still provide minimal or no eyecare services, whilst the cost of private eye care continues to increase beyond the affordability of most South Africans. Optometrists were not included in the public sector because of limited resources which were allocated to what were considered to be "more" essential professionals such as doctors and nurses. Almost two decades post-apartheid, we still do not yet have CS for optometrists. The lack of public health optometrists has led to an increase in the prevalence of visual impairment and blindness ${ }^{7}$. The PBODO has approved the legislation for the introduction of CS for optometry graduates, with the stipulation $^{8}$ that it will commence in 2013. While the inclusion of CS in optometry appears well grounded, the perception and concerns of those who would be affected by the legislation need to be evaluated. No study either locally or internationally, could be found that evaluated the perceptions and opinions of specifically optometry students, regarding the introduction of CS. It is against this background that the present study investigates the perceptions and opinions of graduating optometry students in South Africa on the proposed CS.

\section{Methods}

Ethical approval to conduct this study was obtained from the University of KwaZulu-Natal Research and Ethics Committee (FECHSC 095/10). This study used a mixed (triangulation) method of data collection which consisted of questionnaires and individual interviews. The questionnaire elicited information regarding demographic profiles, perceptions, opinions and concerns regarding CS. The design of the questionnaire was based on a review of existing studies concerning CS but mainly involving psychology $^{1,2}$ and medical students ${ }^{3,4}$ and others ${ }^{9-12}$.

\section{Participants}

The study population included all registered final year optometry students in all institutions offering optometry in South Africa. For the quantitative component, the study sample $\left(N_{1}=119\right)$ comprised of final year optometry students registered at the Universities of Free State (UFS), Johannesburg (UJ), KwaZulu-Natal (UKZN) and Limpopo (UL). There were 129 registered final year optometry students in the four institutions at the time of this study (Heads of Departments, personal communication) and all were included in the study. For the qualitative part, a purposive convenient sampling method was used to select fourteen $\left(N_{2}=14\right)$ participants from the Optometry Department of the University of KwaZuluNatal.

\section{Data gathering}

Following permission from the heads of the four departments of optometry to conduct the survey, questionnaires were distributed in each institution to the graduating optometry students who agreed to participate in the study. The completed questionnaires from each institution were collected by the same staff members. The survey was preceded by a pilot study conducted among five UKZN students (who did not form part of the final study) in order to critically 
evaluate and finalise the questionnaire. All queries concerning the questionnaire during the pilot study were addressed accordingly before the final study was performed.

In depth interviews were conducted by one of the authors (NR) using an interview guide. Due to their transactional nature, the opportunity to observe non-verbal cues and the possibility of probing for clarification, one-on-one interviews were selected to produce data in this part of the study. There were mostly Black (52\%) and Indian (48\%) students, aged between 20 and 28 years (mean age; $21.2 \pm 1.4$ years) and included $56 \%$ females and $44 \%$ males. Semistructured interviews lasting approximately thirty minutes per participant were conducted at a time and site of choice of the participants $\left(N_{2}=14\right)$. This was deemed necessary in light of the busy schedule of final year optometry students. Prior to the interview, participants were informed of their right to withdraw from the study and written consent was obtained from all participants. All interviews were recorded after obtaining permission to do so from the participants. The initial questions were of a personal nature probing the demographic details, followed by general questions regarding participants' perceptions of entering professional optometric practice. Thereafter specific questions regarding their perceptions and opinions of CS in optometry were posed. Follow up questions were asked to clarify the participant's initial responses and as a result varied from one participant to another. Immediately after the interview a member check was performed with all participants. This allowed for preliminary themes, interpreted in the interview to be reviewed with the participants. To ensure credibility of the data, transcripts were sent to the participants for verification of the accuracy of the interviews. Also, a summary of the analysis was given to each participant for member checking. Participants were asked to comment on the correctness or accuracy of the descriptions and impressions derived from the interviews. They were further advised that if the transcriptions did not reflect the contents of the interview as they remembered it, arrangements would be made for the recording to be heard together with the researcher and the transcription amended. None of the participants made any changes or corrections to the original transcripts and all indicated that their transcripts were accurate reflections of their interviews. Thus the interview transcriptions formed textual expressions of the participants' perceptions and opinions of the proposed CS within the optometric profession. All qualitative data was analysed by searching for recurrent and divergent themes.

\section{Data analysis}

The quantitative data from the questionnaires $\left(N_{1}=119\right)$ were collated and analysed descriptively using the Statistical Package for Social Sciences (SPSS) version 18 while transcription and analysis of the qualitative data $\left(N_{2}=14\right)$ began immediately following the interview and was preceded by analysing the transcribed interviews, line by line, highlighting important ideas and themes. Codes were then grouped together and sorted into categories by the interviewer. The data analysis technique of "selecting and highlighting", proposed by van Manen ${ }^{13}$ was applied to all transcripts. This involved reading the transcripts as many times as needed to identify statements and phrases which revealed participants perceptions and opinions of CS. These statements were then highlighted and coded using either a key word or words from the statements. As certain themes reoccurred and became common among the transcripts, the main themes were created on the participants' perceptions and opinions of CS for optometrists. After all the transcripts were coded, all the identified themes were integrated into main themes.

\section{Results}

\section{Quantitative study}

One hundred and twenty nine questionnaires were distributed to the graduating optometry students and 119 students returned the completed questionnaire giving a response rate of $93 \%$. The participant's ages ranged from 20 to 35 years with a mean and standard deviation of $22.8 \pm 2.3$ years and they included $51 \%$ females and $49 \%$ males. They were from the UFS (21.8\%), UJ (25.2\%), UKZN (30.3\%) and UL (22.7\%). There were $43.2 \%$ Blacks, $28.5 \%$ Whites, $19.1 \%$ Indians and $9.2 \%$ Coloureds. They were from urban $(69.8 \%)$ and rural areas (30.2\%). Responses from the participants are shown in Tables 1 and 2. 
Table 1: Percentage of participants who responded to the listed questions on community service $\left(N_{1}=119\right)$.

\section{Question}

Do you think that community service for optometrists will be beneficial to those that have limited or inadequate access to eye care?

Do you think that community service in optometry would be effective in alleviating diseases causing blindness in South Africa?

Do you feel that your (optometric) education has prepared you adequately for community service?

$\begin{array}{lll}\text { Yes } & \text { No } & \text { Unsure } \\ N(\%) & N(\%) & N(\%) \\ 105(88 \%) & 5(4 \%) & 9(8 \%)\end{array}$

$93(78 \%) \quad 9(8 \%)$

$17(14 \%)$

$93(78 \%) \quad 7(6 \%) \quad 19(16 \%)$

Table 2: The relative importance of factors that may influence optometry students to consider community service $\left(N_{1}=119\right)$. Salary and personal safety were considered the most important factors.

$\begin{array}{llll}\begin{array}{l}\text { How important are the following factors to you } \\ \text { regarding community service }\end{array} & \text { Important } & \begin{array}{l}\text { Not } \\ \text { important }\end{array} & \text { Unsure } \\ \text { Salary } & N(\%) & N(\%) & N(\%) \\ \text { Personal safety } & 119(100 \%) & 0(0 \%) & 0(0 \%) \\ \text { Living conditions } & 113(95 \%) & 6(5 \%) & 0(0 \%) \\ \text { Transport } & 108(91 \%) & 11(9 \%) & 0(0 \%) \\ \text { Integration with other health professionals } & 108(91 \%) & 9(8 \%) & 2(1 \%) \\ \text { Provision of holistic experience to eye care } & 105(88 \%) & 3(3 \%) & 11(9 \%) \\ & 93(78 \%) & 9(8 \%) & 17(14 \%)\end{array}$

\section{Qualitative study}

The following summary and discussion highlights the perceptions and opinions of fourteen $\left(N_{2}=\right.$ 14) participants selected from the University of KwaZulu-Natal. Within the main themes, a number of sub-themes were also identified. In describing their feelings about entering professional practice, words such as "excited", "nervous", "scared" and "eager" were common throughout the participants" transcripts. The participants expressed having "mixed feelings" about entering professional optometric practice the following year. This is exemplified by the views of two of the participants. The first participant explained: I am excited and nervous because I am entering a phase where I will be fully responsible for the person's eye care. Also I am excited because of a salary. Another participant said: It is exciting because you know you can go out there and start doing what you planned to do from the beginning (of the degree) and also there is the thought of not having enough

experience to be able to diagnose as quickly... to build up to that level of experience where you do not have to take that much time with your patients. Yes, so I think I have mixed feelings about it.

Some of the reasons given for these diverse feelings included being solely responsible and accountable to patients and the general public for eye care, entering clinical work environments that possibly lack the support of clinical supervisors, feeling inadequate in terms of patient examination and management skills, being aware of challenges that are encountered in professional practice and being able to adapt to the demands of professional practice. Overall participants seemed to be looking forward to the possible challenges of professional practice. This was clearly indicated by one of the participants: It is going to be a challenge to start off there (professional practice) without having your supervisors or anyone watching over you and not there right by your doorstep. I think 
I am quite excited to do that but deep down there might be some fear.

Participants gave positive views of CS being introduced into the optometric profession and stated that CS will enhance their academic and professional development. This is indicated by the view of one participant who said: If you go out there then you would be able to pick it up and get more exposure to such cases. I think that it (community service) is quite okay when it comes to gaining experience and getting exposure as to how it is really out there (in professional practice). Concerning the benefits linked to CS such as the provision of eye care services to the rural communities, some participants spoke very passionately about wanting to make a difference and contributing to the eye care needs of the rural and remote underserved communities in South Africa. For example, a respondent said: I think it is really important because there are a lot of people out there that are not aware that they do not have good vision to function in their daily lives. It is important not only to make them aware but also to go out and reach out to them. So that you know they would be able to function properly and adequately in terms of their vision throughout the day.

Participants also highlighted the impact that CS would have on their personal development. Improvement and expansion of skills related to communication, team work, improvisation and adaptation were also mentioned. It was also felt that CS would give them exposure to various cultures, languages and physical locations that students may not necessarily be exposed to. It was interesting to note that three participants viewed CS as a link between their optometric training and the working world. For example, a participant reported: We are in a comfort zone here (at the training institution) and so I think that in order for us to start practicing in the big world, we need community service. Related to this seemed to be a feeling of comfort knowing that they would have a job after completing their training at the institution. On the other hand, CS in optometry was viewed as less financially rewarding. Participants identified a mismatch between the remuneration in the public and private sector. For example, one participant reported: In the public sector the salary is very bad but if you go to the private sector, the salary is good. So I think there is going be more people in the private than the public (sector). Financial remuneration was of great concern as most of the participants reported incurring financial burdens in the form of student loans during the course of their education. Thus the prospect of having to work for a period of time, while undertaking $\mathrm{CS}$, and not being paid enough money was considered a major disadvantage of implementing CS. However, participants believed that the government had a key role to play in harmonising the current disparity in salaries between the public and private sectors.

Participants also identified the possibility of having to move away from home and being isolated from friends and family as a concern. Other concerns raised included the perception of crime, access to resources and infrastructure such as electricity, transport and safe accommodation. This is exemplified by one of the participants who said: To go far from the environment you have been around for years may be a problem. There would be problems such as crime, lack of accommodation and electricity problems. What if you go to an area that does not have adequate security, accommodation and electricity? Others were concerned about the duration of CS stating that it may delay their future career plans. For example, one participant stated: When it comes to time, you know you plan that at this particular stage in your life you should be doing this. So it (community service) might be seen as a time consuming thing, may be it is a year, or two years but I think it is time consuming.

Language barriers and perceived inconsistencies in the working times between the private and public sectors were raised as possible drawbacks of CS. This is illustrated by the view of one participant: Somehow there is a perception that it is hard working in government (public sector). It is like you need to put in more time and effort when you are in the public sector. The other thing is the language barrier. Noteworthy was the report that many participants highlighted the lack of adequate information about CS from their institutions. Participants recommended that more awareness should be created regarding CS.

\section{Discussion}

A mixed method research design was used in this study in order to get an in depth understanding ${ }^{14}$ of the perceptions and opinions of graduating South African optometry students on the proposed CS. 
Another advantage of the mixed method approach is to cross-check and corroborate different types of data by means of triangulation ${ }^{15}$. For the qualitative component, fourteen participants were chosen from the Optometry Department of UKZN. This site was chosen due to close proximity to the researchers.

Eye-care delivery in South Africa has been grossly inadequate with most of the services being provided by the private sector to economically advantaged communities whilst the vast majority of South Africans are unable to afford private services. The PBODO has applied for the introduction of CS which will provide eye care services to a significant percentage of the population in the rural and remote areas. In addition, it will provide clinical exposure to graduates prior to registering for independent practice. These views are encompassed by Kaye et al $l^{16}$ "Community placement for health professional training regardless of discipline, enhances students' achievement of adaptation and participation in change, application of problem solving in new and future situations with the community serving as a real-life context, creative and critical thinking and adoption of holistic approach to problems and situations. As the students interact with different communities and different providers in the community, the students acquire appreciation of diverse viewpoints".

\section{Quantitative}

The majority of the participants (78-88\%) felt that CS in optometry would be beneficial to those that have limited or inadequate access to eye care; and CS would reduce eye diseases in the country (Table 1). These benefits could be incentives for hard work during the CS. Many of the participants felt that their education has prepared them adequately for CS (Table 1). This is good news as they should be able to function confidently and effectively during the CS. The report that most participants (78\%) felt that CS will provide them with an opportunity to provide holistic care indicates that CS may prove to foster multidisciplinary and interdisciplinary care among various health care professions that have previously been fragmented. This view is supported by the fact that many participants $(88 \%)$ reported that integration with other health professionals is an important factor regarding CS. It is also believed that CS will increase the understanding of course material and enhance personal development. This implies that participants have an intrinsic desire to see their skills impact on the community. These reasons are similar to those cited by medical doctors and dentists who had completed their CS in the past and reflected on its positive outcomes ${ }^{4,17}$.

Other than financial incentives alone, personal safety and general lifestyle considerations such as transport and living conditions (electricity and accommodation) were concerns of the participants. Buykx et $a l^{18}$ reported that the provision of appropriate and adequate infrastructure such as housing and transportation increases professional satisfaction and is essential for quality performance. A similar study among South African doctors listed better accommodation as one of the three most important factors that would influence them to work in rural areas ${ }^{4}$. The findings on lifestyle consideration are expected as students have been reported to be increasingly attracted to "lifestyle friendly" career environments ${ }^{19,20}$. It is note-worthy that personal safety also caused concerns among the participants. Given the high levels of crime and violence in this country, this response is not entirely unexpected. Therefore, the issue of crime will need to be addressed as literature indicates that the number of skilled health personnel intending to migrate abroad has increased considerably over the years because of the perception of crime levels among other factors ${ }^{21-23}$.

\section{Qualitative}

Participants believed that undertaking CS immediately following the end of their training would be valuable to their overall academic and professional development through exposure to a more diverse patient base and the development of practical skills related to patient examination and management. This is illustrated by a concluding comment by one of the participants who said: Community service would be much more of a learning experience for me. I think I would be a better optometrist at the end of the day after the community service. I think that would be the main thing.

South Africa is a diverse country with vast cultural diversity and eleven official languages. It is therefore expected that the participants reported the opportunity to learn other cultures as a positive and important aspect that CS can offer. InAustralia, medical students reported participation in the health care team as well as enjoying social and cultural aspects as valuable experience 
during their internship programme ${ }^{24}$. Participants in the current study felt that their contribution to the health of the community through CS would be substantial and worthwhile. However, the participants raised concerns about possible language barriers and the disparity in salaries between the public and private sector. A competitive remuneration including packaging benefits and bonuses has been reported as important retention strategies for rural and remote health services ${ }^{25-27}$. These incentive programmes may increase the retention of health workers in underserved areas by reducing the strength of some of the reasons why health workers leave such as being away from family and friends, lack of supervisory support and heavy workloads ${ }^{25-27}$. Therefore, rural and scarce skills allowance that the South African government has introduced for CS professionals should be continued and improved upon.

\section{Conclusion}

The general consensus in this study was that the participants acknowledged the importance of CS in making a difference to the eye care needs of many South Africans. The task of preparing new optometry graduates effectively for CS is a shared responsibility among training institutions, the DoH and the HPCSA in order to create an enabling environment for optometric graduates to perform their duties effectively. Optometry can become an integral part of health care in disadvantaged areas and create opportunities for graduating students to sharpen their competencies ${ }^{28}$. South African communities and the graduating optometrists would likely benefit from the CS and it is recommended that the government should do all it can to make CS an enjoyable experience for graduate optometrists by for example, paying attention to the potential concerns raised by the participants of this study. It would also be of interest to conduct a followup study of the experiences of the country's first group of optometrists who undertake CS once it has been implemented in order to compare their perceptions and opinions with the realities of CS.

\section{References}

1. Pillay AL, Harvey BM. The experiences of the first South African community service clinical psychologists. $S$ Afr $J$ Psychol 200636 259-280.

2. Pillay AL, Kramers AL. South African clinical psychology, employment (in) equity and the "brain drain". $S$ Afr $J$ Psychol 200333 52-60.

3. Sibityi HSM, Mdlalose R. Letter to interns re: public service (community service). Department of Health, South Africa 1990.

4. Reid SJ. Compulsory community service for doctors in South Africa: An evaluation of the year. S Afr Med J 2001 91 329-336.

5. Department of Health (DoH). Notice of date of commencement of community service. Government Gazette, Vol 141. No. 23482, Pretoria Government Printers, 2000.

6. Hutchison G. Demographic change. Optician 1995209 2627.

7. Sacharowitz HS. Visual impairment in South Africa: Achievements and challenges. S Afr Optom 200564 139149.

8. Health Professions Council of South Africa (HPCSA). Minutes of the Executive Committee Meeting with Heads of Departments held at Emperors Palace, Kempton Park, South Africa, 5th December 2008.

9. Visser J, Marais M, du Plessis J, Steenkamp I, Troskie I. Experiences and attitudes of dieticians during the first compulsory community service year [2003]. S Afr J Clin Nutr 200619 10-17.

10. Oduntan AO, Louw A, Moodley VR, Richter M, von Poser P. Perceptions, expectations, apprehensions and realities of graduating South African optometry students (PEAR study, 2006). S Afr Optom 200766 94-108.

11. Antonio A, Astin H, Cress C. Community service in higher education: A look at the nation's faculty. Rev Higher Educ 200023 373-97.

12. Bhayat A, Yengopal V, Rudolph MJ, Naidoo U, Vajey A. Attitudes of South African oral hygienists towards compulsory community service. Inter J Dent Hygiene 2008 $68-12$.

13. van Manen M. Researching lived experience: human science for an action sensitive pedagogy. London: The State University of New York Press, 1990.

14. Maree K. First steps in research. Pretoria: van Schaik Publishers, 2007.

15. Schifferdecker KE, Reed VA. Using mixed methods research in medical education: Basic guidelines for researchers. Med Educ 200943 637-644.

16. Kaye DK, Mwanika A, Sekimpi P, Tugumisirize J, Sewankambo N. Perceptions of newly admitted undergraduate medical students on experiential training on community placements and working in rural areas of Uganda. BMC Med Educ 20101047.

17. Naidoo S, Chikte U. Community dental service-the first year. S Afr Dent J 200257 193-196. 
18. Buykx P, Humphreys J, Wakerman J, Pashen D. Systemic review of effective retention incentives for health workers in rural and remote areas: Towards evidence-based policy. Aus J Rur Health 201018 102-109.

19. Lind DS, Cendan JC. Two decades of student career choice at the University of Florida: increasingly a lifestyle decision. Am Surg 200369 53-55.

20. Jutzi L, Vogt K, Drever E, Nisker J. Recruiting medical students to rural practice: perspectives of medical students and rural recruiters. Can Fam Phys 200955 72-73.

21. Oberoi SS, Lin V. Brain drain of doctors from Southern Africa: Brain gain for Australia. Austr Health Rev 2006 30 25-33.

22. Grant HHM. From the Transvaal to the Prainies: the migration of South African Physicians to Canada. J Ethnic Migration Studies 200632 681-695.

23. Bezuidenhout MM, Joubert G, Hiermstra LA, Struwig MC. Reasons for doctor migration from South Africa. $S A$ Fam Pract 200951 211-215.

24. Sen Gupta TK, Muray RB, McDonell A, Murphy B, Underhill AD. Rural internship for final year students: clinical experience, education and workforce. Rur Rem Health 20088827.

25. Nemutandani MS, Maluleke FRS, Rudolph MJ. Community service doctors in Limpopo province. $S$ Afr Med J 200696 180-182.

26. Barninghausen $\mathrm{T}$, Bloom DE. Designing financialincentive programmes for return of medical service in underserved areas: seven management functions. Hum Res Health 2009752.

27. Barninghausen T, Bloom DE. Financial incentives for return of service in underserved areas: a systematic review. BMC Health Ser Res 2009986.

28. Mashige KP, Naidoo KS. Current practices of diagnostic procedures requiring the use of ophthalmic drugs among KwaZulu-Natal optometrists. S Afr Optom 200968180 187. 